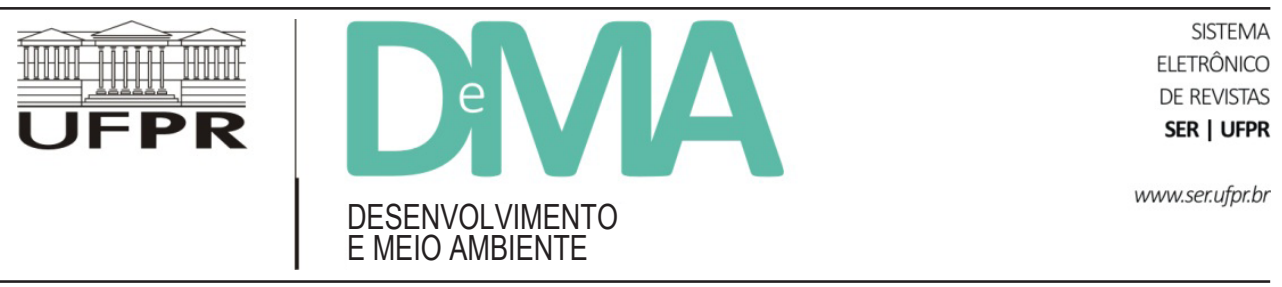

\title{
Pagamentos por Serviços Ambientais na Amazônia: o desvio de um conceito - casos do Amapá e Acre ${ }^{1}$
}

\section{Payment for Environmental Services in the Amazon: the Misuse of a Concept - Amapá and Acre Cases}

\author{
Eliane SUPERTI ${ }^{1 *}$, Catherine AUBERTIN ${ }^{2}$ \\ ${ }^{1}$ Universidade Federal do Amapá (UNIFAP), Macapá, AP, Brasil. \\ ${ }^{2}$ Institut de Recherche pour le Développement, UMR PALOC (IRD/MNHN), Paris, França. \\ *E-mail de contato: esuperti@gmail.com
}

Artigo recebido em 14 de dezembro de 2014, versão final aceita em 22 de agosto de 2015.

RESUMO: Este artigo teve como objetivo apresentar as diversas formas assumidas pelos projetos de Pagamentos por Serviços Ambientais (PSA) no Brasil e analisar dois casos de PSA específicos na Amazônia: o Projeto Carbono Cajari, no sul do Amapá, e o Sistema de Incentivos por Serviços Ambientais (SISA), no Acre. A hipótese de trabalho foi que a apropriação e a reinterpretação da retórica do mercado presentes nas políticas públicas ambientais e nos dois casos em análise são indicadores das tensões presentes nos palcos regional, nacional e internacional, entre o desenvolvimento - com foco no combate à miséria - e a conservação ambiental. A metodologia utilizada foi o estudo de caso, pesquisa bibliográfica e entrevistas. O estudo nos permitiu concluir que os projetos de PSA no Brasil são utilizados mais como dispositivos de transferência de renda do que qualquer mercantilização do meio ambiente ou utilização real das ferramentas de mercado.

Palavras-chave: Pagamento por Serviços Ambientais; Amazônia; ferramentas de mercado; combate à pobreza; gestão ambiental.

ABSTRACT: This paper aimed at presenting the various forms of Payment for Environmental Services (PES) projects in Brazil and analyzing two specific cases of PES in the Amazon: The Cajari Carbon Project in the south of Amapá and the Incentive System for Environmental Services (SISA) in Acre. The hypothesis raised was that the appropriation and reinterpretation of market rhetoric present in environmental public policies, and in both cases under review, are indicators of current pressures on regional, national and international stages, between development - with a focus on fighting poverty - and environmental conservation. The methodology used was case study, literature review and interviews. The study allowed us to conclude that PSE projects in Brazil are

\footnotetext{
${ }^{1}$ Este artigo foi produzido a partir das pesquisas realizadas com o financiamento do Edital Pró-Defesa 03/2013 e do edital 001/2011- FAPEAP e AIRD, que permitiu o desenvolvimento dos projetos de cooperação franco-brasileira BIOFLOR e FRONTAGUI, tendo como instituições parceiras UNIFAP, IRD, CIRAD, Embrapa. (Programa Guyamazon).
} 
used more as income transfer devices than any kind of commodification of the environment or use of marketbased instruments.

Keywords: Payment for Environmental Services; Amazon; market-based instruments; fighting poverty; environmental management.

\section{Introdução}

A discussão sobre pagamento por serviços ambientais (PSA) se insere em um contexto mais amplo de análise das noções de desenvolvimento sustentável e economia verde. Essas expressões foram concebidas no nível internacional e reinterpretadas no Brasil. A reflexão ampliada é necessária para permitir a compreensão do significado do PSA como ferramenta de governança ambiental e a lógica de estruturação dos esquemas para pagamento por serviços ambientais organizados na Amazônia, atualmente.

A noção de desenvolvimento sustentável, utilizada inicialmente pela União Internacional pela Conservação da Natureza, na sua World Conservation Strategy (1980), e posteriormente assimilada e redefinida no Relatório Brundtland da Comissão Mundial pelo Meio Ambiente e Desenvolvimento em 1987 (Montibeller-Filho, 2004), foi considerada pelas organizações internacionais e convencionada entre diversos estados-nações como a principal proposta política e econômica à crise ambiental contemporânea. As questões ambiental e econômica se entrelaçavam, assim, numa ampla rede iterativa e interativa de causa e efeito: se, por um lado, certos tipos de desenvolvimento degradam o meio ambiente, por outro, um ambiente degradado pode ser um obstáculo para o desenvolvimento (Carvalho, 2006). O desenvolvimento sustentável começava, portanto, a ser pautado sobre três princípios centrais: eficiência econômica, equidade e eficiência ecológica, sendo o referido desenvolvimento apresentado como referência para um novo projeto de sociedade.

O desenvolvimento sustentável se configura, então, como uma proposta de racionalização do uso dos recursos naturais e da gestão do meio ambiente, de modo a impedir o esgotamento ambiental, garantindo a manutenção, com ajustes, do modelo econômico vigente. A política ambiental presente nessa proposta estaria, pois, assentada em duas grandes modalidades opostas de regulação: na política dos mecanismos chamados de "comando e controle" (enfatizando o poder de regulação do Estado) e na política de livre mercado e incentivos econômicos (enfatizando o poder de regularização do mercado) (Fernandes, 2006).

Os instrumentos de mercado saíram, dessa forma, da esfera da economia para intervir nas questões ambientais e se tornar ferramentas privilegiadas para a política ambiental. Para os economistas da corrente neoliberal, os incentivos de mercado e os sinais de preços deveriam ser mais eficazes do que as políticas regulatórias para mudar o comportamento dos produtores e dos consumidores (Tietenberg, 1999). Na área da conservação ambiental, a referida corrente afirma que o mercado oferece soluções de menor custo e maior eficiência de processos e tecnologias para minimizar o impacto inflacionário das regulamentações ambientais.

Em consequência, a valorização e a preservação da natureza dependem de sua precificação e mercantilização. Os bens ambientais passam compor um mercado de serviços ambientais e sua valoração depende do quanto os agentes desse mercado (usuários ou consumidores) estão dispostos a pagar. Nesse sentido, o desenvolvimento sustentável está aqui baseado principalmente na racionalidade econômica.

A economia verde se insere nesse contexto, sendo lançada pelo Programa das Nações Unidas para o Meio Ambiente (PNUMA), em 2008. De acordo com o PNUMA (2011, p. 1), fica definida como economia verde "uma economia que resulta em melhoria do bem-estar da humanidade e igualdade social, ao mesmo tempo em que reduz significativamente os riscos ambientais e a escassez ecológica". Em outras palavras, é uma economia de baixa emissão de carbono, de uso eficiente dos recursos naturais e socialmente inclusiva.

A economia verde é apresentada como um novo ciclo de crescimento do capitalismo, baseado no greening (esverdeamento) de toda a economia. O paradigma técnico-econômico verde, que responde ao conceito 
de "ecoeficiência", aparece como o novo horizonte do capitalismo. Produzir mais com menos recursos e menos poluição contribui para uma melhor qualidade de vida. As considerações sobre as mudanças climáticas levaram à pesquisa e à adoção de tecnologias de baixo carbono na área de materiais de construção, planejamento urbano, transportes, agricultura e gestão florestal. Contudo, a modéstia dessas respostas tecnológicas em relação aos objetivos gerais almejados com a economia verde se equivale à fragilidade do pilar social do desenvolvimento sustentável.

Para dar um valor de mercado aos componentes da natureza organizados em torno dos conceitos de externalidades e serviços ambientais, representações de biodiversidade são simplificadas (Daily, 1997; TEEB, 2010). A Convenção da Diversidade Biológica (CDB) sistematizou a defesa do ecossistema, não apenas a defesa de algumas espécies emblemáticas, permitindo a regulação da biodiversidade. Em seguida, os ecossistemas foram apresentados como prestadores de serviços para o bemestar do homem, como serviços ambientais (MEA, 2005). Como a comunidade científica não é indiferente às ações dos operadores de projetos de desenvolvimento, os pagamentos por serviços ambientais tornaram-se, além de ferramentas de conservação, elementos de discussão acadêmica. Tais elementos envolvem: elaboração de conceitos, princípios, definição dos direitos de propriedade, métodos de avaliação monetária, unidades de medida, criação de mercados para os direitos de propriedade, mercados de compensação e outros. O modelo teórico ideal seria, então, a conservação regulada pelo mercado.

Serviços ambientais ou ecossistêmicos são as funções e os processos dos ecossistemas relevantes para a preservação, a conservação, a recuperação, o uso sustentável, a melhoria do meio ambiente e a promoção do bem-estar humano (MEA, 2005).

Os Serviços Ecossistêmicos são de interesse direto ou indireto do ser humano e fornecidos gratuitamente pelo meio ambiente. A tutela jurídica tradicional sobre esses serviços, baseada nos mecanismos de comando-controle e fiscalização, foi julgada como não suficientemente capaz de assegurar a preservação ou a conservação ambiental (Altmann, 2008), o que obedece à tendência ideológica do neoliberalismo, que desacredita qualquer intervenção do Estado em favor da livre iniciativa.
Nessa mesma concepção, a ineficiência da regra jurídica soma-se à lógica capitalista do lucro, que incentiva o desmatamento, a ocupação e o uso degradante do solo em áreas de elevado valor econômico, urbanístico, de produção agrícola ou extrativista.

$\mathrm{Na}$ economia verde, para que o sujeito social deixe de utilizar a área sobre sua propriedade, uso ou posse de modo a auferir ganhos econômicos a favor da conservação/preservação ambiental, ele deve ser compensado. Trata-se do princípio do protetor-recebedor (Furlan, 2008), que, em relação contrária ao poluidor-pagador, busca valorar os serviços prestados à sociedade por aqueles que zelam, cuidam e protegem o meio ambiente. Diferentemente das normas ambientais exclusivamente protetivas-repressivas, esse novo princípio estabelece incentivos positivos que estimulam as condutas de preservação e conservação.

O pagamento por serviços ambientais (PSA) trata da necessidade de valorar a ação humana para guardar, manter, restaurar e usar de forma sustentável as potencialidades ambientais de interesse coletivo. Do ponto de vista jurídico, os serviços ambientais assumem duas naturezas (Rech, 2011). A primeira é o direito existente em potencial na natureza, que não decorre de nenhuma relação jurídica ou autoridade humana. Sobre esse direito não se pode exigir pagamento. Não há como admitir que o homem pague para respirar. A outra natureza jurídica do serviço ambiental são os serviços humanos necessários para conservar e propiciar que a natureza continue prestando seus serviços potencialmente existentes, os quais devem ser remunerados para ser estimulados.

O PSA é um instrumento econômico de gestão ambiental que, baseado no princípio do protetor-recebedor, oferece incentivos para estimular a preservação, a conservação e o uso sustentável do meio ambiente. A descrição de PSA mais aceita pela literatura é a de Wunder et al., que compreende o PSA como:

Uma transação voluntária, na qual um serviço ambiental bem definido ou um uso da terra que possa assegurar este serviço é comprado por, pelo menos, um comprador de, pelo menos, um provedor sob a condição de que o provedor garanta a provisão deste serviço (Wunder et al., 2008, p. 11-12). 
Contudo, segundo Simões \& Andrade (2013), na maioria das vezes, as experiências reais de PSA extrapolam ou não refletem características do conceito. Para os autores, esse hiato entre o aparato conceitual e a realidade dos esquemas de PSA ocorre

devido à simplificação teórica da escola neoclássica, que não consegue abarcar muitas das complicações do mundo real, como a grande importância dos custos de transação, da história de formação e evolução das instituições, além das características específicas de cada ecossistema e sociedade, [...] (Simões \& Andrade, 2013, p. 60).

As experiências de PSA na América Latina, em países como Costa Rica, México, Honduras e Colômbia, têm apontado que os serviços ambientais não compõem mercados reais nos quais são comercializados para compradores como qualquer outro bem. De acordo com Vatn (2010), na maioria dos esquemas de PSA, a "mercadoria" é mal definida e o Estado tem um papel fundamental de intermediário, mobilizando recursos de consumidores para um fundo governamental e posteriormente distribuindo aos ofertantes dos serviços ambientais um preço estabelecido por meio de critérios muito variados que não unicamente o custo-oportunidade.

No Brasil são muitas as experiências de PSA. Todavia, o país não conta com um marco legal sobre PSA e REDD (Redução de Emissões por Desmatamento e Degradação) como ferramenta de governança ambiental. Se a legislação nacional é lenta para se desenvolver, devido à relutância do governo brasileiro em comprometer parte de seus ativos naturais, abrindo mão de forma relativa da soberania sobre seu território, há uma efervescência legislativa nos estados federados, que possuem uma visão mais pragmática e de curto prazo, vendo nos mercados de carbono uma oportunidade de atrair financiamento (veja Tabela 1). Devido à natureza icônica da floresta amazônica, esses instrumentos (PSA e REDD) são aplicados principalmente na luta contra o desmatamento para reduzir as emissões de $\mathrm{CO}_{2}$. Vale ressaltar, contudo, que esses instrumentos de mercado estão longe de ter provado a sua eficácia na proteção do meio ambiente e de se concretizarem por meio de um mercado eficiente e funcional de pagamento de serviços ambientais (Engel et al., 2008; Norgaard, 2010; Gomez-Baggethun et al., 2010; Boisvert et al., 2013).

Nesse artigo, propomo-nos a fazer uma apresentação da ampliação e das diversas formas assumidas pelos projetos de PSA no Brasil, especialmente na Amazônia, discutindo dois casos de PSA: o Projeto Carbono Cajari, no sul do Amapá, e o Sistema de Incentivos por Serviços Ambientais (SISA), do Estado do Acre. Por fim, apontamos como a discussão sobre o PSA é diluída nacionalmente no debate sobre desenvolvimento e combate à miséria, considerando os entraves da utilização dos mecanismos de mercado na política ambiental brasileira.

Nossa hipótese é que a apropriação e a reinterpretação da retórica do mercado, presentes nas políticas públicas e nos dois casos, são indicadores das tensões desenvolvidas nos palcos regionais, nacional e internacional, entre o desenvolvimento - com foco no combate à miséria - e a conservação, entre as ações coletivas e individuais. O nosso objetivo é entender como os interesses nacionais estão transfigurados na política ambiental e de que forma os casos analisados se implementam e revelam a política feita com o meio ambiente no Brasil.

\section{Experiências dos Pagamentos de Serviços Ambientais no Brasil}

A experiência de PSA no Brasil é relativamente recente. Historicamente, a primeira lei que trata de PSA é a da Política Nacional de Recursos Hídricos, de 1997, que permitiu os pagamentos aos que conservavam recursos hídricos, segundo a lógica do protetor/recebedor (Lei 9.433/1997). Esta ideia ecoou também na Lei do Sistema Nacional de Unidades de Conservação (SNUC, Lei 9.985/2000), segundo a qual (arts. 47 e 48) as empresas de abastecimento de água e energia, que se beneficiam da implementação de unidades de conservação, devem participar financeiramente da criação e da proteção da unidade.

Para além dessas leis, o Brasil viveu sua primeira experiência de um programa com previsão de PSA com o Proambiente. Tal programa foi o primeiro a utilizar a expressão "serviço ambiental", buscando combinar a produção agrícola familiar e a conservação ambiental. $\mathrm{O}$ foco era financiar o custo de oportunidade, ou seja, com- 
pensar a perda de renda pela redução do desmatamento e do abandono do uso do fogo. O referido programa teve suas raízes nos movimentos sociais, acompanhando o "Grito da Terra" de 2000. Quando, em 2002, Marina Silva tornou-se ministra do Meio Ambiente, o Proambiente é assumido pelo ministério. Em 2008, 4.000 famílias, distribuídas por 11 centros, foram envolvidas no programa, entretanto, sua implementação foi marcada por grandes dificuldades.

A aproximação dos mecanismos de PSA com a questão de redução da miséria e dos movimentos sociais será uma constante nas experiências brasileiras. Mais recentemente, a Política Nacional de Resíduos Sólidos (PNRS) de 2010 (Lei 12.305) e a Bolsa Verde apontaram nessa direção. A PNRS refletiu o reconhecimento do movimento dos "catadores de lixo", permitindo contratos e parcerias com sindicatos e associações para o pagamento de PSA. A Bolsa Verde, programa de apoio à conservação ambiental (Lei 12.512, de 2011), tem como principal objetivo a promoção da cidadania de pessoas que vivem em extrema pobreza (renda inferior a $\mathrm{R} \$ 70,00$ por mês), em áreas protegidas controladas pela União e que organizam atividades para o uso sustentável dos recursos naturais. Em 2014, o programa abrangeu 73 mil famílias em 11,3 milhões de ha. Esse programa se integra ao programa Bolsa Família e fornece uma renda de $\mathrm{R} \$ 300,00$ por trimestre para famílias cadastradas. O desempenho é supervisionado anualmente pelo Sistema de Proteção da Amazônia (SIPAM).

$\mathrm{Na}$ perspectiva legislativa, a partir de 2007, um projeto de lei sobre pagamentos por serviços ambientais, o ProPSA, passa a ser debatido no Congresso Nacional. Ao texto original, foram apensadas outras 12 versões. Passados sete anos, o texto síntese ainda está em discussão. Além do Projeto de Lei ProPSA, dois outros projetos sobre o sistema nacional de REDD+ tramitam na Câmara dos Deputados e no Senado Federal. Eles enfrentam resistências quanto ao uso dos mecanismos de mercado e certa hostilidade do Itamaraty na relativização do uso e do controle sobre o território nacional. O tema é tratado como uma questão de gestão pública, mas a comercialização de créditos de carbono é colocada em pauta. Os Certificados de Redução de Emissões por Desmatamento e Degradação (CREDD) seriam atribuídos a título de compensações negociáveis no mercado nacional, conforme previsão da Política Nacional de $\mathrm{Mu}$ danças Climáticas, ou dentro de acordos internacionais. Áreas de proteção e reservas legais permanentes (APP e RL, pilares do Código Florestal), além de unidades de conservação e terras indígenas, quilombolas e reservas florestais, seriam elegíveis.

A Política Nacional sobre Mudança do Clima (PNMC - Lei 12.187/2009), para além do plano de ação e dos objetivos de redução de gases de efeito estufa (GES), abrangeu também mecanismos financeiros e econômicos. Ela incentiva o desenvolvimento do mercado brasileiro para pagamento dos serviços ambientais. O Fundo Nacional sobre Mudança do Clima (Lei 12.114/2009) está em funcionamento desde 2011, sendo administrado pelo Ministério do Meio Ambiente, no que diz respeito aos subsídios para a conservação da floresta (R \$ 30 milhões em 2012), e pelo Banco Nacional de Desenvolvimento (BNDES), para os empréstimos para financiar ações de redução aos setores emissores de GES: transporte, resíduos, energia (R $\$ 300$ milhões em 2012). Dez ministros são membros do seu comitê de gestão. Ele é subsidiado principalmente por royalties da lei do petróleo $(9.478 / 1997)$, mas a redistribuição está sendo questionada.

A criação do Fundo Amazônia (Decreto 6.527, agosto de 2008) também somou esforços na direção de viabilizar e organizar no Brasil a prática do PSA. O dito fundo revela ainda a determinação do governo brasileiro de se manter afastado de compromissos multilaterais ou aplicações dos mecanismos de mercado que, de alguma forma, ameacem a sua soberania sobre a Amazônia. Os doadores (principalmente Noruega) recebem um "diploma", mas não créditos de carbono em troca de sua contribuição. O Fundo Amazônia é o principal financiador de projetos de preparação para aplicação de REDD+ existentes no Brasil. O Fundo já investiu na Amazônia Brasileira mais que qualquer outro fundo multilateral.

A reforma do Código Florestal (Lei 12.651/2012) completa esse quadro, prevendo a criação de sistemas de pagamento por serviços ambientais e compensações para agricultores familiares, envolvidos na conservação e na valorização dos ecossistemas (Capítulo 10). A sua implementação deverá promover a reformulação de conceitos sobre REDD+ e PSA presentes nos projetos de leis em discussão, além de gerar a obrigatoriedade do 
cadastramento das propriedades rurais e a restauração das áreas ilegalmente degradadas.

Apesar destas iniciativas, a ausência de um marco legal nacional que imprima um padrão regulatório e de organização dos esquemas de PSA possibilitou o surgimento de experiências variadas quanto à legislação, às escalas de ação e aos contextos nos Estados e até nos municípios. As experiências mais comuns são voltadas a recursos hídricos e sequestro de carbono. Os projetos de PSA são organizados com uma grande variedade de mecanismos de financiamento, como o pagamento direto pelos usuários, o comércio nos mercados de carbono, os fundos governamentais, os fundos privados e mistos.

Como na maioria dos países da América Latina, a maior parte dos programas de PSA no Brasil foca-se nos serviços de proteção aos recursos hídricos e se concentra na metade sul do país. Isso também se justifica pela Política Nacional de Recursos Hídricos, que já apontava a possibilidade de PSA, e pelo projeto Produtores de Água, da Agência Nacional de Águas/ANA, iniciado em 2006, que estimulou Estados e municípios a organizarem seus esquemas de PSA. Os projetos de sequestro de carbono encontram-se mais dispersos, com uma concentração na região amazônica (Tabela 1).

$\mathrm{Na}$ maioria dos projetos, tanto de carbono quanto de recursos hídricos, os mecanismos de financiamento estão vinculados a agências, fundos ou ONGs e utilizam fórmulas variadas para gerar uma tabela que relaciona os valores de pagamento, condições e níveis específicos de serviços e benefícios ambientais (Pagiola et al., 2012). Por vezes, não há claramente estabelecida a relação entre pagamento, identificação e valoração de um serviço ambiental.

A Tabela 1 aponta as legislações ou iniciativas estaduais específicas que tratam de PSA, os projetos estaduais ou com participação dos governos estaduais e os mecanismos de financiamento previstos.

Como retratado na Tabela 1, é intensa a organização nos Estados e as iniciativas se expandem também para os municípios. Dois municípios no Estado de Minas
Gerais, Extrema e Montes Claros, foram os primeiros no Brasil a estabelecer programas de PSA com objetivos de proteção aos serviços ambientais da bacia hidrográfica em 2006. Segundo levantamento do Instituto Brasileiro de Geografia e Estatística - IBGE, 418 ou 7,5\% das prefeituras municipais brasileiras efetuam pagamentos por serviços ambientais, sendo que o Centro-Oeste é a região do país onde esse instrumento é mais aplicado.

Apesar de compreendido com um instrumento de gestão ambiental, existe em relação ao PSA, tanto nos municípios quanto nos Estados, grande expectativa quanto ao papel que os mercados de serviços ambientais podem desempenhar em relação à geração de renda e melhoria de qualidade de vida de populações rurais empobrecidas (Veiga Neto, 2008). A sinergia do PSE com a questão social pode ser resultado tanto da transferência de recursos dos beneficiados pelos serviços ambientais para grupos empobrecidos quanto do estímulo à sua organização, ou ainda do desenvolvimento de práticas de trabalho mais sustentáveis. O uso do PSA como instrumento de gestão ambiental, associado a mecanismos de redução da pobreza, pode gerar a situação econômica de "ganha-ganha2", pois não só melhora as condições de vida e desenvolvimento econômico de grupos específicos como também promove a preservação, a recuperação ou o uso sustentável dos recursos naturais. Essa associação permite superar a estreiteza do conceito de PSA formulado no âmbito da economia neoclássica e ampliar o seu potencial socioambiental.

No entanto, é preciso lembrar que PSA não pode substituir a política social ou os investimentos em serviços públicos básicos, cuja falta ou deficiência é muitas vezes a causa central das situações de pobreza existentes na Amazônia, por exemplo. O que foi possível apreender da maioria dos projetos é que a sigla PSA é usada sem implementação efetiva de qualquer mecanismo de mercado ou sem qualquer transação econômica real. Situação paradoxal, que se repete nos dois casos analisados, embora, como já discutido, o PSA seja uma ferramenta econômica de gestão ambiental.

\footnotetext{
${ }^{2}$ Expressão utilizada no ambiente de negócios para designar uma situação incomum em que todos os envolvidos em uma transação comercial ganham com a negociação.
} 
TABELA 1 - Legislações e projetos de Pagamento por Serviços Ambientais (PSA) nos Estados brasileiros.

\begin{tabular}{|c|c|c|c|}
\hline Estado & Legislação que trata de PSA & Projeto de PSA & Mecanismo de Financiamento \\
\hline Acre & $\begin{array}{l}\text { Lei Estadual } 2.308 / 2010 \text { - Sistema de Incentivo a } \\
\text { Serviços Ambientais do Acre }\end{array}$ & $\begin{array}{l}\text { *Sistema de Incentivos a Serviços } \\
\text { Ambientais (SISA) }\end{array}$ & Misto (público e privado) \\
\hline Alagoas & Não encontrado & - & - \\
\hline Amapá & $\begin{array}{l}\text { Projeto de Lei 036/2010 - PSA no Estado do } \\
\text { Amapá }\end{array}$ & **Projeto Carbono Amapá & Misto (público e privado) \\
\hline Amazonas & $\begin{array}{l}\text { Lei Estadual 3.135/2007 - Política Estadual de } \\
\text { Mudanças Climáticas. } \\
\text { Decreto Estadual 26.958/2007 cria o Programa } \\
\text { Bolsa Floresta }\end{array}$ & *Programa Bolsa Floresta & Misto (público e privado) \\
\hline Bahia & $\begin{array}{l}\text { Projeto de lei } \mathrm{n}^{\circ} 20.863 / 2014 \text { - Política Estadual } \\
\text { de PSA }\end{array}$ & *Programa Estadual de PSA & Misto (público e privado) \\
\hline Ceará & Não encontrado & $\begin{array}{l}\text { **Projeto de fixação e sequestro de } \\
\text { carbono Fundação CEPEMA }\end{array}$ & $\begin{array}{l}\text { Sem mecanismo de financiamento } \\
\text { definido }\end{array}$ \\
\hline Espírito Santo & Lei n ${ }^{\circ} 8.995 / 2008$ - PSA & *Programa ProdutorES de Água & Público \\
\hline Goiás & Lei n ${ }^{\circ} 18.104 / 2013$ - Programa de PSA & $\begin{array}{l}\text { **Programa Produtor de Água do João } \\
\text { Leite }\end{array}$ & Público \\
\hline Maranhão & Não encontrado & $\overline{-}$ & - \\
\hline Mato Grosso & $\begin{array}{l}\text { Projeto de Lei de agosto de } 2013 \text { - PSA e do } \\
\text { Fundo Estadual de PSA }\end{array}$ & **Projeto Poço de Carbono Juruena & Misto (público e privado) \\
\hline Mato Grosso do Sul & $\begin{array}{l}\text { Lei } 2406 / 2002 \text { - Política Estadual de Recursos } \\
\text { Hídricos }\end{array}$ & *Manancial Vivo - Campo Grande & Público \\
\hline Minas Gerais & $\begin{array}{l}\text { Lei Estadual } 17.727 / 08 \\
\text { Decreto } 45.113 / 09\end{array}$ & $\begin{array}{l}\text { *Programa Bolsa Verde. Recursos } \\
\text { hídricos }\end{array}$ & Público \\
\hline Paraná & $\begin{array}{l}\text { Lei } 17134 / 2012 \text { - PSA } \\
\text { Decreto Estadual } 4.381 / 2012 \text { Programa Bioclima } \\
\text { Paraná }\end{array}$ & $\begin{array}{l}\text { *Programa Bioclima. Biodiversidade e } \\
\text { recursos hídricos }\end{array}$ & Misto (público e privado) \\
\hline Paraíba & Lei n $^{\circ} 10.165 / 2013$ - Política Estadual de PSA & *Programa Estadual de PSA & Público \\
\hline Pará & $\begin{array}{l}\text { Projeto de Lei de setembro de } 2009 \text { - Política } \\
\text { Estadual de Mudanças Climáticas do Pará }\end{array}$ & $\begin{array}{l}\text { **REDD+ Calha Norte. Projeto } \\
\text { REDD em são Félix do Xingu. Projeto } \\
\text { Ecomapuá, Ilha do Marajó. Projeto } \\
\text { REDD Cikel }\end{array}$ & Misto (público e privado) \\
\hline Pernambuco & $\begin{array}{l}\text { Lei Estadual 14.090/2010 - Política Estadual de } \\
\text { Enfrentamento às Mudanças Climáticas }\end{array}$ & $\begin{array}{l}\text { **Projeto Água do Parque. Recursos } \\
\text { hídricos }\end{array}$ & Misto (público e privado) \\
\hline Piauí & $\begin{array}{l}\text { Projeto de lei de abril de } 2010 \text { - Política Estadual } \\
\text { de Mudanças Climáticas e Combate à Pobreza. }\end{array}$ & *Projeto Bolsa Verde/APA do Rangel & Público \\
\hline Rio de Janeiro & $\begin{array}{l}\text { Lei 3.239/1999 - Política Estadual de Recursos } \\
\text { Hídricos }\end{array}$ & *Programa Estadual de PSA & Misto (público e privado) \\
\hline $\begin{array}{l}\text { Rio Grande do } \\
\text { Norte }\end{array}$ & Não encontrado & - & - \\
\hline Rio Grande do Sul & $\begin{array}{l}\text { Projeto de lei } 011 / 2012 \text { Política Estadual de } \\
\text { Serviços Ambientais }\end{array}$ & $\begin{array}{l}\text { *Programa Estadual de pagamento por } \\
\text { Serviços Ambientais. }\end{array}$ & Público \\
\hline Rondônia & $\begin{array}{l}\text { Projeto de Lei } 792 / 2007 \text { - Política Estadual de } \\
\text { PSA }\end{array}$ & **Projeto Carbono Florestal Suruí & Misto (público e privado) \\
\hline Roraima & Não encontrado & - & - \\
\hline Santa Catarina & $\begin{array}{l}\text { Lei } 15.133 / 2010 \text { - Política Estadual de Serviços } \\
\text { Ambientais }\end{array}$ & *Programa Estadual de PSA & Público \\
\hline Sergipe & Não encontrado & - & - \\
\hline São Paulo & $\begin{array}{l}\text { Lei Estadual 13.798/2009 - Política Estadual de } \\
\text { Mudanças Climáticas }\end{array}$ & $\begin{array}{l}\text { *Programa Estadual de Remanescentes } \\
\text { Florestais. }\end{array}$ & Público. Fundo Estadual \\
\hline Tocantins & $\begin{array}{l}\text { Lei Estadual 1.917/2008 - Política Estadual sobre } \\
\text { Mudanças Climáticas, Conservação Ambiental e } \\
\text { Desenvolvimento Sustentável do Tocantins. }\end{array}$ & $\begin{array}{l}\text { ** Projeto Taquarussu: uma Fonte de } \\
\text { Vida }\end{array}$ & Misto (público e privado) \\
\hline
\end{tabular}

* Projeto compõe a legislação estadual citada.

${ }^{* * *}$ Projeto sem vinculação direta à legislação estadual citada.

FONTES: Assembleias Legislativas Estaduais. Ministério do Meio Ambiente/Secretaria de Mudanças Climáticas e Qualidade Ambiental. Fundo Amazônia. Idesam - Instituto de Conservação e Desenvolvimento Sustentável do Amazonas. Imazon - Instituto do Homem e Meio Ambiente da Amazônia. Secretaria do Meio Ambiente do Estado de São Paulo. Coordenadoria de Biodiversidade e Recursos Naturais (2012). 


\section{PSA na Amazônia: casos do Acre e do Amapá}

AAmazônia legal brasileira abrange mais de cinco milhões de quilômetros quadrados em áreas muitas vezes de difícil acesso. Isso faz com que uma política ambiental que se ampare em mecanismos de comando, controle e fiscalização implique altos custos de implantação. Além disso, muitos dos mais de 500 mil pequenos agricultores na Amazônia Legal não poderiam cumprir com a legislação ambiental sem comprometer, em muitos casos, sua baixa qualidade de vida (Peixoto, 2011).

No cenário amazônico, a proposta de PSA, especialmente de pagamentos para reduzir o desmatamento (REDD+), tem como foco principal o aumento de renda de populações tradicionais e empobrecidas, que são provedoras de serviços ambientais, mas não a redução de emissões de GES. Acredita-se que, com o PSA, pequenos agricultores podem ser estimulados a arranjos produtivos locais sustentáveis, gerando a situação de "ganha-ganha".

No intento de interpretar os esquemas de pagamentos por serviços ambientais utilizados na Amazônia brasileira, discutiremos dois casos emblemáticos. O primeiro caso estudado é o do Carbono Cajari, no Amapá, que não se distingue de um projeto de desenvolvimento rural e apoio a populações extrativistas. O outro caso é o Sistema de Incentivo aos Serviços Ambientais (SISA), do governo estadual do Acre, cuja organização prevê uma série de ferramentas de acompanhamento e medição, que estão de acordo com as normas internacionais, para mensurar os serviços de sequestro de carbono e oferta dos créditos a investidores internacionais.

\subsection{Caso do Amapá - Carbono Cajari}

O Amapá, assim como parte significativa da Amazônia brasileira, apresenta grande potencial de oferta de serviços ambientais relacionados à biodiversidade e à retenção de carbono em florestas naturais. Vale ressaltar que $72 \%$ do território amapaense possui alguma restri- ção de uso, pois são Unidades de Conservação (UC) e Terras Indígenas (TI) vinculadas à jurisdição federal ou estadual. O governo do Estado, na carta do Amapá para a Rio+20, propôs a organização de PSA a moradores locais ligados ao uso sustentável, à proteção e à conservação dessas áreas.

Este cenário indica que PSA de conservação seriam economicamente viáveis - fato confirmado com o recente acordo assinado com a empresa britânica Permian $\mathrm{Ba}$ sin Royalty Trust. Segundo o representante da empresa no Brasil, "o Amapá está entre as áreas prioritárias de interesse para investimentos em negócios ligados à conservação do ecossistema"3. A proposta foi encaminhada em caráter experimental, em que a empresa demonstrou interesse em contribuir para a concretização de projetos de REDD numa parte destinada para isso na Floresta Estadual, conhecida como Flota 4.

Por outro lado, a grande restrição de uso do território faz com que os municípios sofram a virtualidade do poder de gestão, pois são detentores do ato administrativo, mas não têm poder real para ordenamento de uso do solo. A virtualidade do poder municipal, associada à significativa carência técnica e limitações na capacidade institucional, pode impactar negativamente em esquemas de PSA com pagamentos diretos a moradores locais, pois tais esquemas dependem de mecanismos flexíveis e eficientes para o repasse de pagamentos a moradores em localidades remotas, o que representa um desafio para administrações locais com pouca infraestrutura para a implementação de políticas ambientais sem gestão do território.

Apesar dos desafios, no Amapá, os esquemas de PSA tendem a se organizar com foco nos arranjos produtivos locais de comunidades tradicionais e extrativistas em áreas de UCs como políticas públicas estaduais indutivas. O Projeto Carbono Cajari - Comunidade e Agroextrativismo da Castanha na RESEX-CA, atuou diretamente com populações tradicionais agroextrativistas de uma unidade de conservação federal, a Reserva Extrativista do Rio Cajari (RESEX-CA), localizada no sul do Amapá, Estado da Amazônia setentrional brasileira.

${ }^{3}$ IEF e parceiros reúnem com Empresa Britânica. 14/02/2012. Disponível em: <http://ief.ap.gov.br/conteudo/lista_noticias/94>. Acesso em: 09 ago. 2014. 


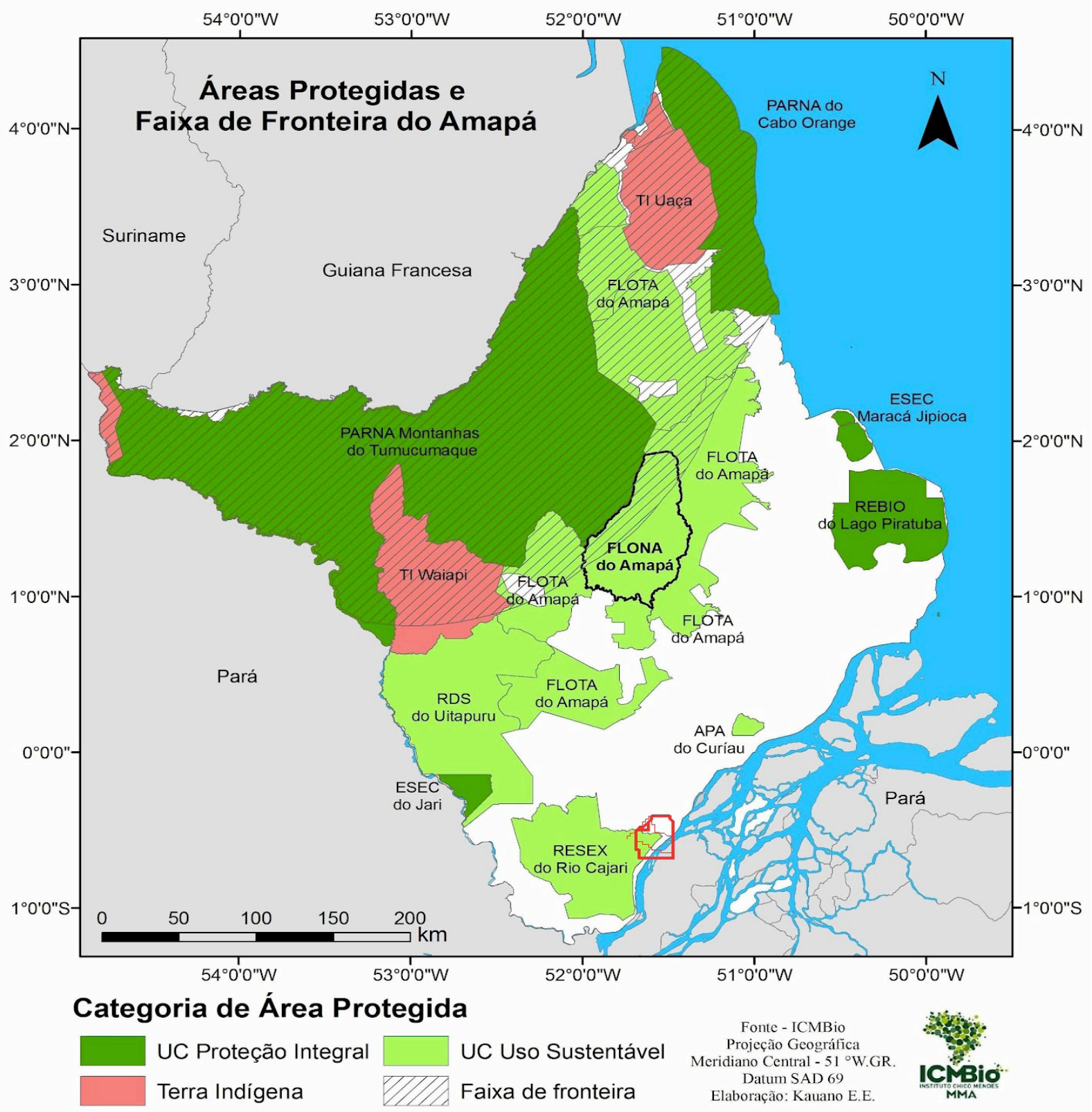

FIGURA 1 - Áreas Protegidas e Faixa de Fronteira no Amapá.

FONTE: ICMBio (2014). 
O objetivo do projeto foi "trabalhar com as comunidades tradicionais a fixação de carbono e emissões evitadas pela conservação das florestas e da biodiversidade associada ao bioma amazônico, contribuindo no combate ao aquecimento global e às mudanças climáticas ${ }^{4}$. $\mathrm{O}$ cumprimento do objetivo deu-se por meio da expansão de populações naturais de castanheiras, da educação ambiental e do investimento na cadeia produtiva da castanha do Brasil para fortalecimento do extrativismo, da conservação das florestas e da biodiversidade associada ao bioma amazônico.

A castanha possui forte importância patrimonial, considerando que a Bertholletia excelsa é uma espécie vulnerável, que aparece na lista vermelha da UICN (União Internacional para a Conservação da Natureza). O seu manejo é símbolo da luta dos extrativistas organizada por Chico Mendes para conseguir direitos sobre as suas terras, a fim de lutar contra o desmatamento e promover um desenvolvimento sustentável que garantisse a conservação da floresta. Sendo assim, o projeto liga diretamente as práticas agroextrativistas aos serviços ambientais gerados.

O projeto foi desenvolvido em 14 comunidades, nas quais mais de 1.400 pessoas foram envolvidas diretamente, ao longo de sua execução. Ele teve como proponente a Associação dos Trabalhadores Agroextrativistas da Reserva Cajari (ASTEX-CA), uma associação sem fins lucrativos que trabalha na organização social e atende aos agroextrativistas da região do "alto Cajari”, onde se concentram os castanhais na Resex. A execução foi realizada por uma equipe contratada e parceiros institucionais (Empresa Brasileira de Pesquisa Agropecuária - EMBRAPA/Amapá, Instituto Estadual de Florestas - IEF - e Instituto Chico Mendes de Conservação da Biodiversidade - ICMBio), além de organizações não governamentais (Conselho Nacional das Populações Tradicionais - CNS, Associação de Mulheres do Alto Cajari - AMAC, Cooperativa Mista dos Trabalhadores Agroextrativistas do Alto Cajari e Escolas-Famílias Agroextrativistas do Maracá e do Carvão - EFAEX-MA e EFAC). Foram as organizações não governamentais que desenvolveram o projeto e são elas as fornecedoras dos serviços ambientais (SA).
As ações foram divididas em cinco linhas de atuação:

1) Mapeamento participativo de aproximadamente 330 castanhais (mais de 30.000 ha e 70.000 castanheiras georreferenciadas) para quantificação da produção e do potencial de emissões evitadas - pagamento de bolsas para 20 estudantes das escolas-famílias agroextrativistas;

2) Fixação de carbono por meio da expansão e do manejo de castanheiras jovens dentro da área do roçado - 340 famílias de extrativistas monitoradas;

3) Melhoria da infraestrutura e dos processos de coleta, armazenamento, beneficiamento e transporte da produção, por meio da implantação de novas tecnologias - desenvolvimento de um secador solar de castanha e construção de 65 silos para armazenamento, além da construção das cozinhas comunitárias, da reforma de instalações e da aquisição de veículos;

4) Capacitação ambiental, produtiva e gerencial realização de inúmeras oficinas de educação ambiental em todas as comunidades, além de treinamentos técnicos e administrativos para público específico;

5) Apoio à administração do projeto, gestão das associações e cooperativa, além da implantação de infraestrutura de comunicação e divulgação para adoção de práticas sustentáveis. A comunicação foi um dos principais focos para divulgação e disseminação do conhecimento gerado.

O projeto melhorou a compreensão da dinâmica da castanha e apoiou as atividades produtivas das comunidades tradicionais. Entretanto, ele difere pouco dos projetos convencionais de desenvolvimento rural, o que leva à questão sobre o rótulo "carbono" do projeto e sobre o fato de que ele é apresentado como um exemplo de pagamentos por serviços ambientais (PSA).

A referência ao carbono foi feita especificamente para adequar o projeto à proposta do edital da Petrobras Ambiental, que disponibilizou R \$ 3.500.000,00 sobre a linha de atuação "Fixação de carbono e emissões evitadas com base na conservação de florestas e áreas naturais e reconversão de áreas produtivas". Os parceiros institucionais investiram, como contrapartida, $\mathrm{R} \$ 500.000,00$.

\footnotetext{
4 Projeto Carbono Cajari. Apresentação do Projeto, Edital Petrobras Ambiental, 2010.
} 
O projeto fomentou ainda o estudo e a implantação do sistema "castanha na roça", que contribuiu no combate às mudanças climáticas de duas formas: expansão dos castanhais (que teriam elevado o potencial de retenção do carbono) e redução das emissões, já que minimizou o uso do fogo no preparo das áreas de plantio.

Apesar de envolver a quantificação do potencial de emissões evitadas, do sequestro de carbono dos castanhais e do estoque de carbono nos solos da região, por meio de implementação de parcelas experimentais, fica nítida a prioridade dada ao fortalecimento da cadeia produtiva. A minimização do uso do fogo nas áreas de plantio se resume à proteção das castanheiras.

$\mathrm{O}$ projeto e sua forma de execução não deixam clara a noção de pagamentos de serviços ambientais, ou como a valoração, a certificação e a compensação pelo sequestro de carbono seriam efetivadas. O projeto não menciona também a possibilidade de remuneração das populações pelos serviços ambientais, restringindo-se a apontar a sustentabilidade financeira das comunidades após a execução do projeto, que se daria pelo fortalecimento da cadeia produtiva da castanha e do aproveitamento rápido de alternativas econômicas que promovam o pagamento por serviços ambientais.

Assim, esse projeto de desenvolvimento socioeconômico, de promoção do saber tradicional e com forte enfoque ambiental, tem por estratégia geral o alívio da pobreza, o melhoramento das condições de vida (eletricidade, água, estradas), além do estímulo econômico ao núcleo familiar extrativista, por meio do investimento ao longo da cadeia produtiva, reconhecendo que as populações extrativistas tiveram um papel histórico importante para a manutenção da floresta amazônica conservada e de sua biodiversidade.

O projeto é coerente com a política definida pelo Estado do Amapá na preparação para a Rio +20. Ele se distancia, contudo, da questão da valorização do PSA em favor do apoio direto às populações. Não há como separar três itens: extrativismo sustentável, educação ambiental e inclusão social. É preciso facilitar e melhorar a vida das pessoas que dependem da atividade, resolvendo gargalos como a logística de transporte, as dificuldades de comercialização e os problemas de gestão das organizações sociais. É isso que gera sustentabilidade social e econômica, além da garantia de conservação da floresta pela regeneração dos castanhais.

Qual é, então, o serviço ambiental? Os responsáveis pelo projeto não hesitam: “o serviço ecológico é o valor agregado da castanha ao serviço da conservação e da expressão dos habitantes da Resex; ou seja, um modo de vida" ${ }^{5 "}$. Este serviço ambiental (SA) proporciona um "incremento da vida dos cidadãos em um mundo globalizado 6 ". Algumas dúvidas aparecem sobre a sustentabilidade das atividades implementadas pelo projeto. Assim, o ICMBio não aproveitou o projeto para concluir o plano de manejo da Resex.

\subsection{Caso Acre - Sistema de Incentivos por Serviços Ambientais do Acre (SISA)}

Desde a luta de Chico Mendes, que levou à criação de reservas extrativistas e à divulgação do conceito de Florestania - crescimento econômico com inclusão social e conservação ambiental -, o Estado do Acre tem se posicionado vis-à-vis à comunidade internacional como um defensor da floresta amazônica. Para tanto, o Estado se apropriou rapidamente de ferramentas de conservação presentes nas negociações internacionais, tais como pagamentos por serviços ambientais e mecanismos de REDD. O Acre tem ainda se apresentado como um bom candidato aos financiamentos internacionais, com $86 \%$ de sua cobertura florestal intacta, tendo metade de seu território sob o estatuto de áreas protegidas (Figura 2) e uma taxa de desmatamento que caiu 71\% entre 2003 e 2012.

O Acre foi um dos primeiros Estados a implementar legislação sobre serviços ambientais, inspirada explicitamente na experiência do Proambiente e promovendo um balanço sobre seus limites. A Lei n ${ }^{\circ} 2.308$, de 22 de outubro de 2010, instituiu o Sistema de Incentivo aos Serviços Ambientais (SISA), facilitando a implementação de projetos de REDD, com o programa (art. 20) de Carbono ISA. O SISA tem por objetivo conciliar desen-

\footnotetext{
5 Entrevista de campo, 2014.

${ }^{6}$ Projeto Carbono Cajari. Apresentação do Projeto, Edital Petrobras Ambiental, 2010.
} 


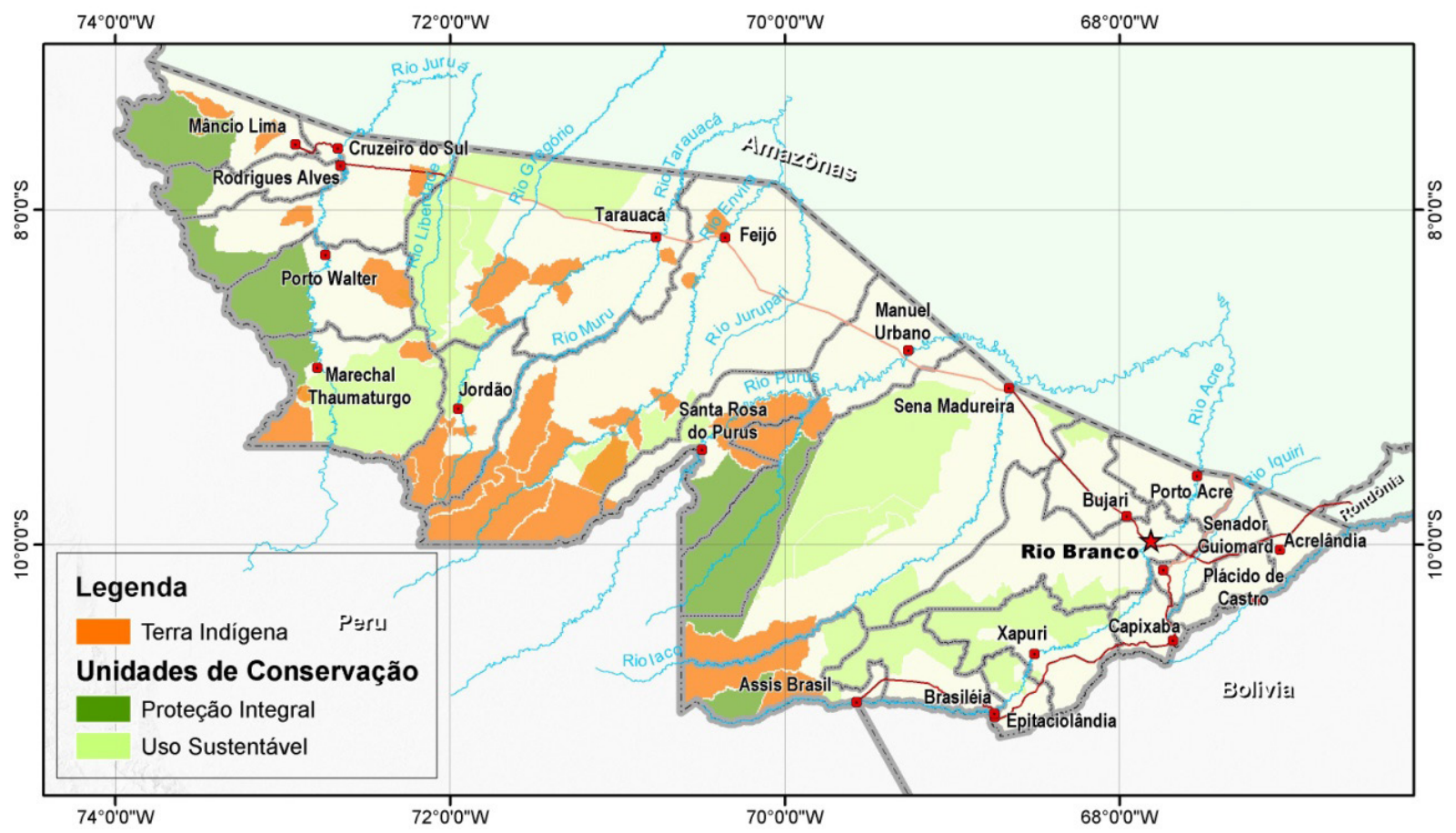

FIGURA 2: Mapa das Áreas Naturais Protegidas

FONTE: Acre em Números (2011).

volvimento econômico com a conservação das florestas e contribuir para a luta contra as alterações climáticas. Ele está claramente apresentado como uma estratégia de captura de fundos. E o decreto 1.471, publicado um ano depois da lei que instituiu o SISA, organizou o arranjo institucional para a viabilização dessa estratégia com a criação do Instituto de Mudanças Climáticas e Regulação dos Serviços Ambientais (IMC).

O IMC é o responsável pela inspeção, pela certificação e pelo registro de resultados da Companhia de Desenvolvimento dos Serviços Ambientais (CDSA). Trata-se de uma empresa que incentiva acordos de parceria com o setor privado. A lei do SISA e o decreto 1.471 foram promulgados graças à forte atuação do governador Jorge Viana, envolvido com as questões ambientais desde 1999, às ações do Fórum de Secretários de Meio Ambiente da Amazônia e ao Grupo GCF (Força Tarefa de Governadores sobre Clima e Florestas). O SISA foi também objeto de várias consultas públicas, mas o governo federal permaneceu fora do processo.
A força do SISA está em integrar um conjunto de políticas públicas voltadas para a valorização dos ativos ambientais florestais: incentivos para serviços ambientais, regulação de passivos ambientais, certificação de unidades de produção sustentáveis, gestão de florestas públicas, privadas e comunitárias e recuperação de áreas degradadas. O sistema se apoia no zoneamento econômico-ecológico (ZEE), que define quatro grandes eixos:

1. Consolidação dos sistemas de produção sustentável - uso sustentável de recursos naturais e proteção ambiental;

2. Florestas prioritárias para o desenvolvimento territorial;

3. Centros urbanos;

4. Verificação do estado das áreas protegidas controle via satélite e georreferenciamento das propriedades. 
Apesar de tomar por base o ZEE, o SISA traz uma lógica de marketing que o diferencia e que está voltada para o mercado internacional, centralizada nos créditos do carbono, como demonstra o programa ISA Carbono. O ISA Carbono se apresenta como um dos maiores regimes de REDD+ do mundo. Para conduzi-lo com sucesso até 2012, R\$ 107.000.000,00 foram investidos. Cinco grupos socioeconômicos foram identificados como público-alvo do programa: famílias indígenas, famílias de extrativistas, assentados (menos de 100 hectares), propriedades privadas (mais de 100 hectares) e outras terras públicas. $\mathrm{O}$ valor dos investimentos necessários para implantar as ações, com o objetivo de evitar a emissão de GES, é considerado custo oportunidade. Ele varia de $0,11 \mathrm{US} \$ / \mathrm{tCO}_{2}$ nas áreas indígenas a 2,21 US\$/ $/ \mathrm{CO}_{2}$ nos assentamentos. O programa é ambicioso e compreende todo o Estado do Acre: $164.221 \mathrm{~km}^{2}$, inclusive as áreas federais e propriedades privadas e 30.000 estabelecimentos rurais (WWF, 2013).

O Acre alinhou-se ao objetivo de redução do desmatamento definido para a Amazônia pela política nacional, que trata de mudanças climáticas do governo brasileiro, ou seja, $80 \%$, que equivale a um desmatamento de $120 \mathrm{~km}^{2}$ em 2020. Entretanto, o Estado não leva em conta os modos de cálculo definidos pelo Fundo Amazônia, conservando somente uma linha de base entre 2005-2020 (sem reajuste a cada 5 anos, segundo a metodologia do Fundo) e uma estimativa de 123 toneladas de carbono por hectare (quando o Fundo aplica a norma de 100 tC/ha). Para garantir a credibilidade do sistema, os créditos carbono foram validados pela VCS (Voluntary Carbon Standard) e pela CCBA (Climate, Community and Biodiversity Alliance). Surpreendeu-nos o fato de essas agências de certificação não levarem em consideração as normas estabelecidas em escala nacional.

Em dezembro de 2012, o KFW, banco de desenvolvimento alemão, partindo da base de dados de redução de emissão atingida pelo Acre, comprometeu-se em investir 16 milhões de euros durante 4 anos, o que corresponde ao pagamento de 4 milhões de $\mathrm{t} \mathrm{CO}_{2}$, avaliadas em 5 US\$/t. Não se trata da venda de créditos carbono no mercado voluntário. Tal soma não provém de uma demanda do governo alemão ou de empresas alemãs, a fim de compensar suas emissões de $\mathrm{CO}_{2}$, mas de impostos que o governo alemão recolhe das transações do mercado europeu do carbono (ETS). A liberação de tal verba foi registrada como uma doação, não como uma venda, a fim de evitar cobrança de impostos pelo governo brasileiro.

Trata-se de um acordo de cooperação financeira, uma ajuda ao desenvolvimento considerando as condições ambientais. Esse acordo permite contornar as reticências do governo brasileiro e do Itamaraty concernentes à possibilidade, pelos Estados federados, de negociar seus créditos de carbono, independentemente dos acordos internacionais do Brasil junto à Convenção Climática da ONU e da Política Nacional sobre Mudança do Clima (PNMC).

O governo do Acre acredita na sua capacidade de encontrar novos financiamentos e está preparando quatro projetos REED que poderiam interessar ao Estado da Califórnia (EUA), além de São Paulo e Rio de Janeiro (Brasil). Se o Acre atingir seus objetivos de redução, ele gerará uma oferta de 118 milhões de $\mathrm{tCO}_{2}$ entre 2012 e 2020 - metade do que poderia absorver a demanda potencial mundial de créditos carbono no período intermediário, antes da execução do sistema de Convenção Climática. Assim, a demanda da Califórnia, principal comprador no mercado voluntário, poderia absorver somente $68 \%$ desse montante ( 80 milhões de toneladas) e o FCPF se responsabilizará em absorver o complemento, com uma capacidade de compra de somente 43,8 milhões de toneladas (IFF, 2014).

A lei do SISA não se limita a proporcionar um quadro jurídico para retribuir e estimular os serviços ambientais. Ela vai além, propondo uma política de desenvolvimento fundada num setor inovador da economia do século XXI: a valorização da conservação do meio ambiente e dos ativos florestais. A experiência do Acre reforça a importância do apoio político de um programa governamental global, no qual possam se inserir projetos, estruturas jurídicas - leis e instituições - adaptadas e meios de controle. A experiência do SISA, apesar de recente, aponta que uma política integrada é capaz de atrair fundos nacionais e internacionais. 


\section{Considerações finais}

As leis e os programas que acabamos de comentar não se vinculam, de forma direta, ao quadro dogmático dos PSA, tal como é definido por autores como Wunder et al. (2008) ou Engel et al. (2008), embora os resultados dos casos trabalhados sejam, ainda, parciais. É perceptível, contudo, que fazem parte, com a mesma nomenclatura, transferências sociais, sistemas de compensação, bonificações, contratos, bolsas de ativos ambientais, expectativas nas transações com créditos carbono, etc. Eles consistem em acordos institucionais abrangendo diversos órgãos públicos - raramente o setor privado, frequentemente a sociedade civil.

A definição do serviço ambiental é ampla, atribuindo uma grande importância aos serviços culturais, de um lado (que, segundo a política de desenvolvimento inclusivo, abrangem primeiramente o bem-estar dos pequenos agricultores e o apoio a seus modos de produção e de organização), e, de outro, aos serviços de sequestro de carbono por meio dos mecanismos REDD+. Os beneficiários são os agricultores familiares, as comunidades tradicionais e os povos indígenas; mas as categorias fundiárias elegíveis não estão definidas. Com exceção dos "créditos carbono" ofertados no mercado, o valor do financiamento estipulado no contrato do PSA não está vinculado ao cálculo de valorização, ou até mesmo à definição do serviço ambiental. A lógica do sistema está baseada no pressuposto de que a mudança de comportamento das populações florestais não depende do pagamento por serviços ambientais, mas de investimentos diretos na transformação dos sistemas produtivos. Os benefícios previstos permitem, assim, estimular as iniciativas comunitárias e institucionais. Entretanto, vale questionar a eficácia destes pagamentos quando eles são em torno de R\$100,00/mês por família.

Os recursos mobilizados provêm de fundos públicos (federais e estaduais), com previsões de doações provenientes do governo ou de países estrangeiros. Esses fundos são distribuídos segundo uma lógica de subvenção. Os programas ou os fundos podem financiar iniciativas com selos de REDD+ ou de PSA, sem que esses programas estejam vinculados a uma lógica de mercado. Não encontramos, na verdade, instrumentos de mercado claramente definidos, exceto os projetos de leis nacionais REDD+ e PSA, o Código Florestal e a lei que rege os serviços ambientais do Acre, em sua versão carbono.

$\mathrm{Na}$ maioria dos casos, os pagamentos se assemelham a transferências sociais. O mercado é evocado, assim, como uma simples metáfora econômica e a referência aos serviços ambientais é essencialmente estratégica, no intuito de chamar a atenção e assim poder captar recursos financeiros oriundos de fundos diversos. Os projetos estão mais focados na oportunidade de captação de recursos que de fato na promoção do pagamento pela preservação ou oferta de serviços ambientais.

Em função de certa tensão entre a União e os Estados federados, não sabemos se os ativos de carbono provenientes de projetos REDD+ estaduais poderão ser comercializados nos mercados voluntários ou nos mercados regulamentados pela Convenção Climática.

Os PSA têm um efeito performático, que entendemos como uma reavaliação das políticas públicas e dos dispositivos de transferência de renda, bem antes de qualquer mercantilização do meio ambiente. No Brasil, a conservação ambiental pelos mecanismos de mercado é um mito, e estamos aqui na presença de dispositivos de incentivos públicos aos projetos de desenvolvimento e de conservação florestal dos mais clássicos.

A atenção internacional voltada ao mecanismo REDD+ oblitera a situação real, no que diz respeito ao controle do Brasil sobre seus territórios. Podemos citar o exemplo da reforma do Código Florestal, em que os proprietários são obrigados, por exemplo, a reflorestar suas reservas legais desmatadas indevidamente, o que abre os mercados de ativos ambientais. Das 5,6 milhões de propriedades rurais cadastradas pelo IBGE, 4 milhões deverão reflorestar suas reservas legais. Entre 30 e 60 milhões de hectares estão envolvidos (Soares Filho, 2013), estimativa bem superior à superfície com desmatamento evitado reivindicada pelos planos REDD+. Pela sua importância em termos de remanejo do território e de conservação, da imensidão das superfícies e das emissões de carbono em jogo, esta reforma atualmente é assumida pelo governo como o principal projeto REDD+ do Brasil. A Estratégia Nacional de REDD+ (ENREDD) explica claramente que, após ter preenchido as condições do RED (luta contra o desmatamento), o Brasil entra na 
fase do REDD+ (com o destaque para a conservação, a gestão sustentável das florestas e do reforço dos estoques de carbono florestal), por meio da aplicação de seu novo
Código Florestal (MMA, 2013). Será provavelmente a reforma do Código Florestal que definirá o futuro dos PSA e REDD, no Brasil.

\section{Referências}

Altmann, A. Pagamento por serviços ecológicos: uma estratégia para restauração e preservação da mata ciliar no Brasil? Caxias do Sul, Dissertação (Mestrado em Direito) - Universidade de Caxias do Sul, 2008.

Boisvert, V.; Meral, P.; Froger, G. Market-Based Instruments for Ecosystem Services: Institutional Innovation or Renovation? Society \& Natural Resources: An International Journal, 0, 1-15, 2013.

Carvalho, D. F. Desenvolvimento Sustentável e seus limites teóricos metodológicos. In: Fernandes, M.; Guerra, L. $O$ contradiscurso do desenvolvimento sustentável. 2. ed. Belém: NAEA, 2006.

Daily, G. C. Nature's services: Societal dependence on natural ecosystems. Washington, DC: Island Press, 1997.

Engel, S.; Pagliola, S.; Wunder, S. Designing payments for environmental services in theory and practice: An overview of the issues. Ecological Economics, 65, 663-674, 2008.

Fernandes, M. Desenvolvimento Sustentável: antinomias de um conceito. In: Fernandes, M.; Guerra, L. O contradiscurso do desenvolvimento sustentável. 2. ed. Belém: NAEA, 2006.

Furlan, M. A função promocional direito no panorama das mudanças climáticas: a ideia de pagamento por serviços ambientais e o princípio do protetor-recebedor. São Paulo, Tese (Doutorado) - PUC, 2008.

Gomez-Baggethun, E.; Groot, D. R.; Lomas, P.; Montes, C. The history of ecosystem services in economic theory and practice: From early notions to markets and payment schemes. Ecological Economics, 69(6), 1209-1218, 2010.

IFF - Interim Forest Finance. Stimulating Interim Demand for REDD+Emission Reductions: The Need for a Strategic Intervention from 2015 to 2020. January 2014. 50 p.

Montibeller-Filho, G. O mito do desenvolvimento sustentável: meio ambiente e custos sociais no moderno sistema de produtor de mercadorias. 2. ed. rev. Florianópolis: Ed. da UFSC, 2004.

MEA - Millennium Ecosystem Assessment. Ecosystems and human well-being: Synthesis. Washington, DC: Island Press, 2005.
MMA - Ministério do Meio Ambiente. Estratégia nacional de REDD do Brasil. Documento para consulta pública. Brasília: Secretaria de Mudanças Climáticas e Qualidade Ambiental, $2013.73 \mathrm{p}$.

Norgaard, R. B. Ecosystem services: From eye-opening metaphor to complexity blinder. Ecological Economics, 69(6), 1219-1227, 2010.

Pagiola, S.; Glehn, H. C. Von; Taffarello, D. Experiências do Brasil em Pagamentos por Serviços Ambientais. In: São Paulo (Estado). Secretaria do Meio Ambiente/Coordenadoria de Biodiversidade e Recursos Naturais. Experiências de pagamentos por serviços ambientais no Brasil. São Paulo, 2012.

Peixoto, M. Pagamento por Serviços Ambientais: aspectos teóricos e proposições legislativas. 2011. Disponível em: $<$ http://www.senado.gov.br/senado/conleg/textos_discussao/ TD105-MarcusPeixoto.pdf $>$. Acesso em: junho 2012.

PNUMA. Caminhos para o Desenvolvimento Sustentável e a erradicação da pobreza: síntese para tomadores de decisão. 2011. Disponível em: <www.unep.org/greeneconomy > Acesso em: 09 set. 2013.

Rech, A. U. O valor econômico e a natureza jurídica dos serviços ambientais. In: Rech, A. U. Direito e Economia Verde: natureza e aplicações práticas do pagamento por serviços ambientais, como instrumento de ocupações sustentáveis. Caxias do Sul: Educs, 2011.

Santos. P.; Brito, B. Regime legal federal de PSA. In: Santos, P.; Brito, B.; Maschietto, F.; Osório, G.; Monzoni, M. (Org.). Marco Regulatório sobre pagamento por serviços ambientais no Brasil. Belém, PA: IMAZON; FGV; CVces, 2012.

Simões, M.; Andrade, D. C. Limitações da abordagem coaseana à definição do instrumento de Pagamento por Serviços Ambientais (PSA). Sustentabilidade em Debate, 4(1), 59-78, 2013.

Soares Filho, S. B. Impacto da revisão do código florestal: como viabilizar o grande desafio adiante? Brasília: Secretaria de Assuntos Estratégicos, 2013.

Taschizawa, T. Gestão ambiental e responsabilidade social corporativa: estratégias de negócios focadas na realidade brasileira. 6. ed. São Paulo: Atlas, 2009. 
TEEB - The Economics of Ecosystems and Biodiversity. The economics of ecosystems and biodiversity: Ecological and economic foundations. London: Earthscan, 2010.

Tietenberg, T. H. Tradable Permit Approaches to Pollution Control: Faustian Bargain or Paradise Regained? Waterville: Department of Economics, Colby College, 1999.

UICN, UNEP, WWF. World Conservation Strategy. Gland: Living Resource Conservation for Sustainable Development, 1980.

UNEP - United Nations Environment Programme. Abrace o verde - Os setores privados pioneiros já participam de um futuro sustentável: a oportunidade da Rio+20 para oferecer políticas de transformação que acelerem a sustentabilidade em todo o setor empresarial. Disponível em: $<$ http://www.unep. org/pdf/Business_Case-16June-Newsdesk-Draft_PR_PT-BR. pdf $>$. Acesso em: 12 set. 2012.
Vatn, A. An institutional analysis of payments for environmental services. Ecological Economics, 69(6), 1245-1252, 2010.

Veiga Neto, F. C. da. A construção dos mercados de pagamentos por serviços ambientais e suas implicações para o desenvolvimento sustentável no Brasil. 2008. Rio de Janeiro, Tese (Doutorado) - Programa de Pós-Graduação em Desenvolvimento, Agricultura e Sociedade - CPDA, Universidade Federal Rural do Rio de Janeiro - UFRRJ, 2008.

Wunder, S.; Borner, J.; Tito, M. R.; Pereira, L. Pagamentos por serviços ambientais: perspectivas para a Amazônia Legal. Brasília: MMA, 2008.

WWF-Brasil. O sistema de incentivos por serviços ambientais do Estado do Acre, Brasil: lições para políticas, programas e estratégias de REDD Jurisdicional, 2013. 80 p. 